\title{
Accurate Stress Analysis on Steel Box Girder of Long Span Suspension Bridges Based on Multi-Scale Submodeling Method
}

\author{
Hao Wang ${ }^{1,2, *}$, Aiqun $\mathrm{Li}^{1}$, Ruomei Hu${ }^{1}$ and Jian $\mathrm{Li}^{2}$ \\ ${ }^{1}$ College of Civil Engineering, Southeast University, Nanjing 210096, P.R. China \\ ${ }^{2}$ Department of Civil and Environmental Engineering, University of Illinois at Urbana-Champaign, Urbana, IL 61801, U.S.A.
}

(Received: 2 January 2009; Received revised form: 16 November 2009; Accepted: 17 November 2009)

\begin{abstract}
The streamline flat steel box girder is broadly used in long span cablesupported bridges all over the world. As one of the most important part of the bridges, its stress level and distribution under various dynamic loads are especially concerned. However, it is difficult to obtain the accurate stress of the steel box girder by common finite element (FE) calculation. The Runyang Suspension Bridge (RSB) is taken as an example. To increase the accuracy of results, a 3-dimensional FE full model for the RSB is created by ANSYS and a spatial submodel of the steel box girder is particularly built with greater detail. Submodeling method is then employed as a connection technique to link different scale models. After the global analysis and connecting process, the local stress of the steel box girder under various vehicle loads is obtained by submodel analysis. The composite action between the full model and the submodel is analyzed, and the reasonable mesh size for the submodel is specially investigated. The numerical results are proved to be accurate by the field test results. This study demonstrates the reliability and efficiency of the submodeling method; and can provide references for accurately analyzing and designing the steel box girders of other long span bridges.
\end{abstract}

Key words: suspension bridge, multi-scale, finite element (FE) modeling, steel box girder, submodeling method.

\section{INTRODUCTION}

Finite element method (FEM) has been extensively used in modern structural engineering arena. An accurate and reliable FE model plays a critical role in the studies on structural health monitoring and condition assessment, wind-resistance and earthquake-resistance analysis, vibration control, etc. Therefore, many research studies have been focused on the FE model updating technique based on experimental data in order to achieve a FE benchmark model which is suitable for different analysis objectives (Mottershead et al. 1993; Ou 2003; Zhang and Sun 2002; Jaishi and Ren 2005; Wang et al. 2005).
Although all of the structural analyses results should be accurate, there are different degrees of accuracy needed at different locations in a bridge under different loading conditions. The streamline flat steel box girder is one of the examples. The streamline flat steel box, owing to its distinguished performance, has been broadly employed in long span bridges since it was firstly used in Severn Bridge in England in 1996. A common way to simulate the steel box girder is employing the simplified spine FE model; however, due to the lack of detail, its coarse FE mesh fails to fulfill the requirements for analyzing the stress level and assessing the fatigue condition of the real steel box girder. 
In order to obtain more accurate results in the stress analysis of certain region like the steel box girder, two options are available. One is reanalyzing the entire model with greater mesh refinement. However, it might be computationally too expensive to perform the stress analysis on the full model of such a super-long span suspension bridge, due to the fact that too many elements and nodes are modeled. Furthermore, building a large scale finite element model with too much detail will introduce more uncertainties hence will increase the possibility of errors in analysis. Another option is using multi-scale FE modeling technique which refines the model only within the region of our interest. In the multiscale modeling, models of different scale are linked together by using connection technique. Considering its advantages and great potential to give more accurate result while maintaining relatively low computational demand, study on multi-scale FE modeling technique, as well as its connection technique, is of great significance (Cormier et al. 1999; Chan et al. 2003).

In this paper, the steel box girder of the Runyang suspension bridge (RSB) with a main span of $1490 \mathrm{~m}$ is selected as an engineering background. According to different objectives during the structural health monitoring and safety assessment, the RSB is analyzed by multi-scale FE modeling technique and its steel box girder is particularly studied by submodeling method. Then the numerical results are validated by experimental results of the field test, which provides theoretic references for analyzing and designing steel box girder of long span bridges.

\section{THE SUBMODELING METHOD}

The submodeling method is an effective way of analyzing the local stress of large complex structures, and it has been successfully applied in a few existing engineering projects around the world. For example, the submodeling method has been used for the analysis of orifice of stress concentrations (Cormier et al. 1999; Sinclair et al. 2000), high arch dam (Che and Song 2003), the deck structure of long span cable-stayed bridge (Xu et al. 2004), the double-lap composite adhesive bonded joint (Bogdanovich and Kizhakkethara 1999), the bonded joints for ship structures (Wang et al. 2004) and other complex structures (De Langhe et al. 1997; Rabinovich and Sarin 1996). However, the application of the submodeling method on engineering structures is still at the beginning stage. More specifically, the examples of large scale bridges are rare. On the other hand, the world has been witnessing the mushrooming of super large and complex structures, along with the rapid progress in design methodology and construction technologies. This will inevitably raise challenges to the stress analysis of complex structures. Therefore, the submodeling method is a promising technique in solving such demanding engineering problems.

The basic steps of the submodeling method are as follows:

(1) Perform global analysis. The full model is meshed with coarse grids, excluding the local structural details, and then the displacements on the cut boundary can be calculated.

(2) Create the submodel. The submodel should be created according to the dimensions and constructions of the substructure, as well as the requirements of the analysis objective. Proper elements should be selected for the submodel. It is obvious that the grid density of the submodel should be increased to a higher level than the global model.

(3) Perform cut boundary interpolation. Not all the nodes along the cut boundaries are one-to-one mapped between the full model and the submodel. For those mapped nodes, apply displacements from the global model directly on the submodel counterparts; for non-mapped nodes, calculate the displacements at these nodes by interpolating between adjacent nodes from the full model. This is a key step in submodeling.

(4) Duplicate on submodel any other boundary conditions and loads on the full model, and apply interpolated boundary displacements on it at the same time.

As mentioned above, the submodeling method is more advanced than the traditional method on stress analysis of the steel box girder of long span bridges (Hsu and Fu 2002; Sennah and Kennedy 2002). Submodeling, however, is based on St. Venant's principle which assumes the cut boundaries are far enough away from the stress concentration region. This assumption should be adequately satisfied to achieve reasonable accurate results.

\section{STRUCTURAL FINITE ELEMENT (FE) MODELING}

\subsection{Overview of RSB}

The RSB is a single-span hinged and simply supported suspension bridge with a main span of $1490 \mathrm{~m}$, as shown in Figure 1. By the time of this study, it is the longest suspension bridge in China and the third in the world.

In the RSB, there are three spans, two towers and cables. The main span contains suspenders at an interval of $16.1 \mathrm{~m}$ and rigid central buckles which is firstly used in suspension bridge in China. The two side spans, with the length of $470 \mathrm{~m}$, include no suspender. With the 

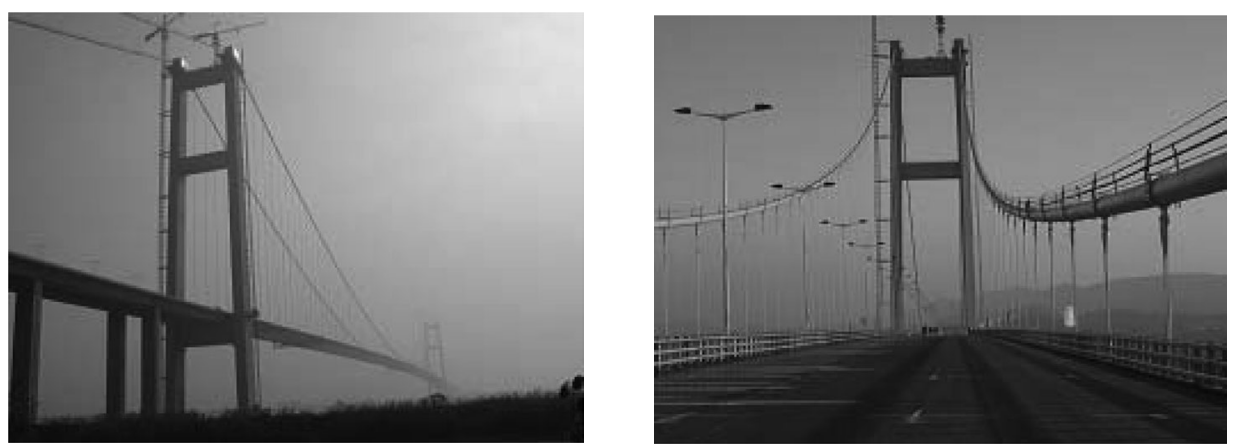

(a) Two photos of RSB

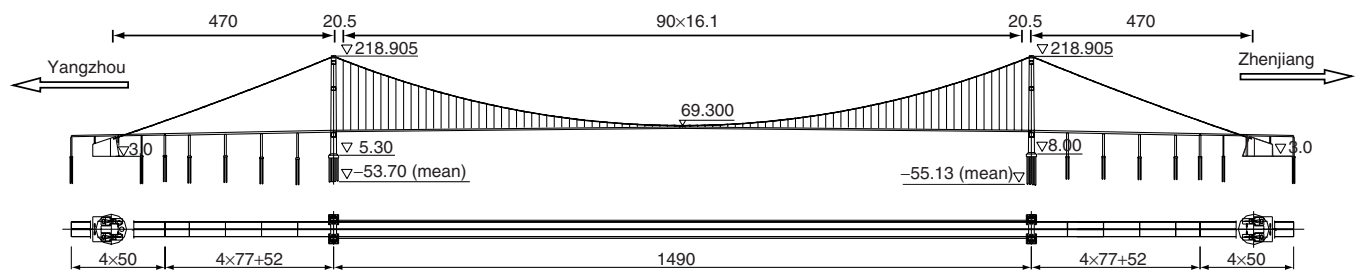

(b) Elevation and plan (Unit: m)

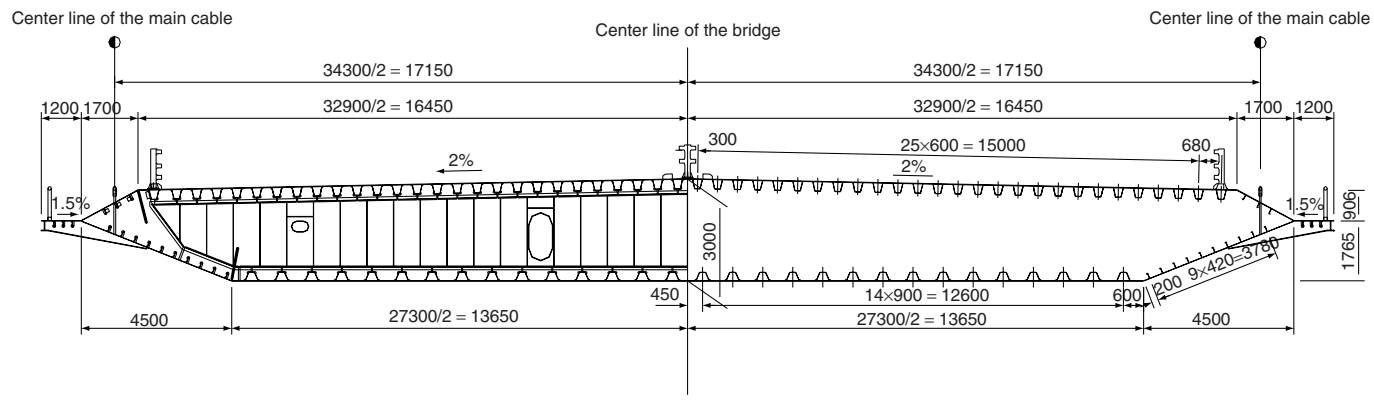

(c) Cross-section of the steel box girder (Unit: $\mathrm{mm}$ )

Figure 1. Configuration of RSB

height of $218.905 \mathrm{~m}$, the two towers employ the multistory structure with two columns and three crossbeams. In the tower column, the single-box single-room crosssection is used. The main cable is made up of 184 prefab parallel subsection cables and each subsection cable contains 127 high-strength steel wires.

The welded streamline flat steel box girder is employed as the main girder of the RSB. The length of the main girder is $1485.16 \mathrm{~m}$ which is divided into four segments, including the end-span segment, mid-span segment, near-mid-span segment and standard segment. The standard segment includes 84 parts, with the length of $1352.40 \mathrm{~m}$ for the entire segment and $16.1 \mathrm{~m}$ for each part. The width of the main girder, including wind mouth and road for examining and repair, is $38.7 \mathrm{~m}$ and the height of the main girder at the middle is $3.0 \mathrm{~m}$. Q345-D steel is mainly used in the main girder. The thickness of the steel deck on the main girder is $14 \mathrm{~mm}$, and the thickness of the top " $U$ " girder under the top plate and the bottom "U" girder above the bottom plate is $6 \mathrm{~mm}$. The distance between the transverse clapboards is $3.22 \mathrm{~m}$.

The stress of $1 / 2,1 / 4$ and $1 / 8$ section of the main girder of RSB are analyzed by submodeling method, using ANSYS program (Swanson Analysis Systems Inc 2004). The numerical results are compared with experimental results from the field test. The accuracy and reliability of the method are validated by field measurements. Considering the similarity of the analysis procedure, only the $1 / 4$ section is taken as an example in the study. 


\subsection{Full Model}

A 3-dimensional full model for the RSB, shown in Figure 2, is built in ANSYS program according to the design. In this model, the central buckle (the first time employed in the suspension bridge in China) and the towers are simulated by spatial beam elements with six degrees of freedom for each node. The main girder is simulated by four-node shell element, and the standard segment is meshed according to the nodes of the suspenders and midpoints of the adjacent suspenders in the longitudinal direction. The transverse clapboard, the top and bottom plates are meshed according to the distance of the " $U$ " girder in the transverse direction.

The main cables and the suspenders are simulated by 3-dimensional linear elastic truss element with three degrees of freedom for each node (Chan et al. 2003). The main cables and the deck are meshed according to the nodes of the suspenders. The pavement and the railings on the steel box girder are simulated by lumped mass element which provides no rigidity. The material

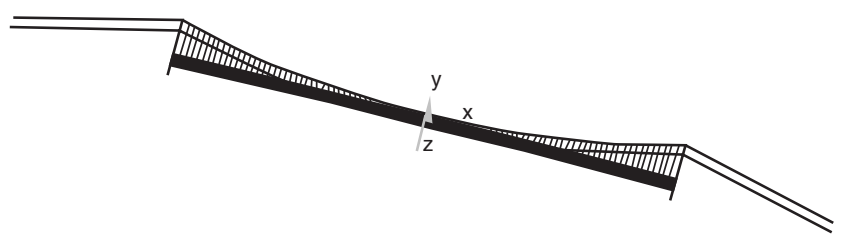

Figure 2. The full model properties and real constants of the structure are strictly calculated according to the design and assigned to the simulated elements. The nonlinear stiffness characteristic of the back cables due to gravity effect is approximately simulated by linearizing the cable stiffness using the Ernst equation of equivalent modulus of elasticity (Ernst 1965). All of the corresponding material properties and the real constants of the elements are listed in detail in $\mathrm{Li}$ et al. (2006).

The deck and the corresponding crossbeams of the towers are coupled in three degrees of freedom including the vertical displacement, the transverse displacement and the rotation around the longitudinal direction. As the first time application in China, the central buckle is precisely simulated and coupled with the deck and the main cables according to the design. Considering the significance of the connection between the main cables and the two towers, the configuration of the main cable saddle is given in Figure 3.

According to the design of the main cable saddle in RSB as shown in Figure 3, the main cable could be stably clamped by the main cable saddle installed on the top of the tower, hence there is no relative displacement between the main cable and the main tower after the bridge is finished and open to the traffic. Therefore, the main cables are fixed on the top of the towers in the full model.

Because the two main towers of RSB are made of reinforced concrete and are supported by rigid foundations, the bottoms of both towers are fixed at the

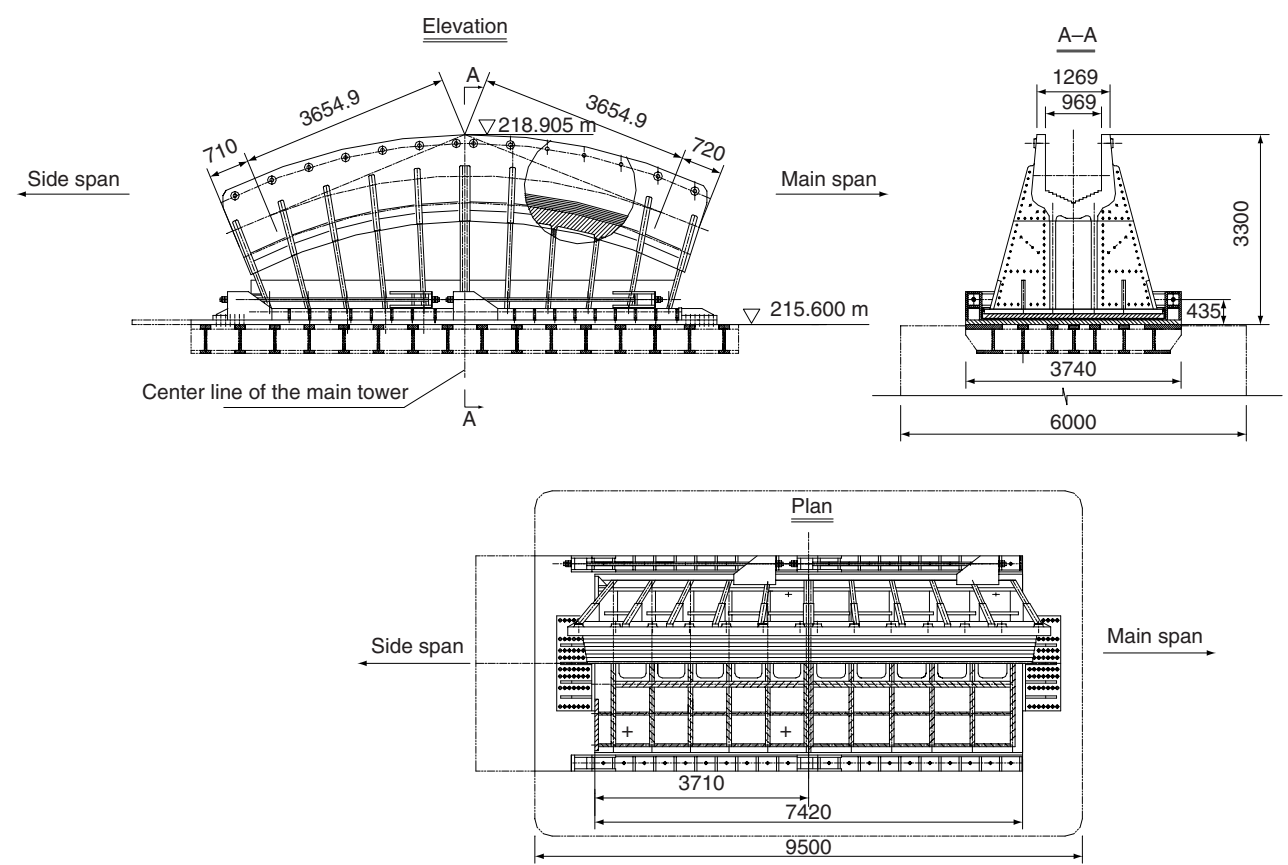

Figure 3. Configuration of the main cable saddle in RSB (Unit: mm) 
bases. There is no displacement permitted at the bottom of the back cable, so the two back cables at the end of the side spans are also are fixed at the bases.

Since the distance between two adjacent suspenders is $16.1 \mathrm{~m}$, the length of each shell element of one standard part is $8.05 \mathrm{~m}$ in the longitudinal direction. Because the deck is meshed according to the distance of the "U" girder, the width of each shell element is $0.30 \mathrm{~m}$ on the top plate and $0.45 \mathrm{~m}$ on the bottom plate in the transverse direction, respectively. It is obvious that the mesh on the full model is too coarse in the longitudinal direction to achieve accurate stress analysis results. However, the increase in the grid density will result in huge number of elements, since the total element number of the full model is already 18660 . Therefore, it is necessary to employ the submodeling method for accurate stress analysis.

\subsection{Submodel}

The steel box girder of the standard segment is submodeled 3-dimensionally, strictly based on the original design. The length of the submodel (including two parts) is $32.2 \mathrm{~m}$, as shown in Figure 4.

In the submodel of the steel box girder, the top and bottom plates, the "U" girder, the wind mouth and the transverse clapboard are all numerically modeled by four-node shell element. The material properties and real constants are also validated by comparing with the corresponding design values. The total element number of the submodel is 42241. It is obvious that the grid density increases greatly compared to that of the full model, and the density of the stress concentration region in submodel is higher than that of common parts ( Li et al. 2007). The length and the grid density of the submodel are proved to be adequate in Section 5.1.

\subsection{Submodel Analysis}

After creating the full model and the submodel of the steel box girder of RSB, cut boundary interpolation process is programmed by using APDL (ANSYS Parametric Design Language) in ANSYS, and the connection of the submodel and the full model is shown in Figure 5. Then the stress analysis results are achieved as follows.

Firstly, the structural displacements of the full model under all kinds of load cases are analyzed. Then, the nodes on the cut boundary of the submodel are identified and their displacements from the full model are automatically applied on these nodes. Moreover, the temperature loads, the tension forces of the suspender and the vehicle loads are also applied on the submodel after the analysis type and option are defined. In details, the tension force of the suspender is simulated by concentrated force, and the vehicle loads are simplified as concentrated forces in the full model analysis while as equivalent surface loads in the submodel. Finally, the
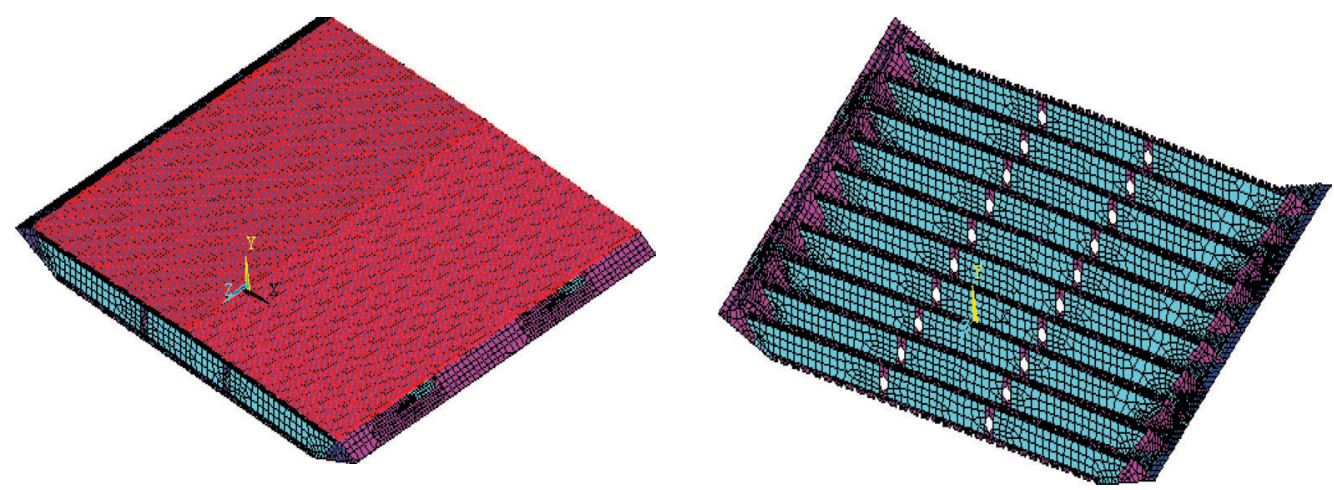

Figure 4. The submodel of the steel box girder
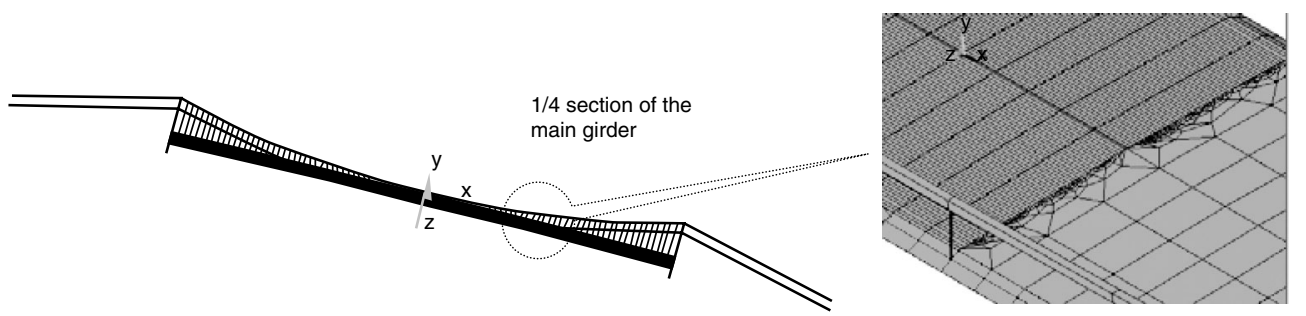

Figure 5. The connection of the submodel and the full model 


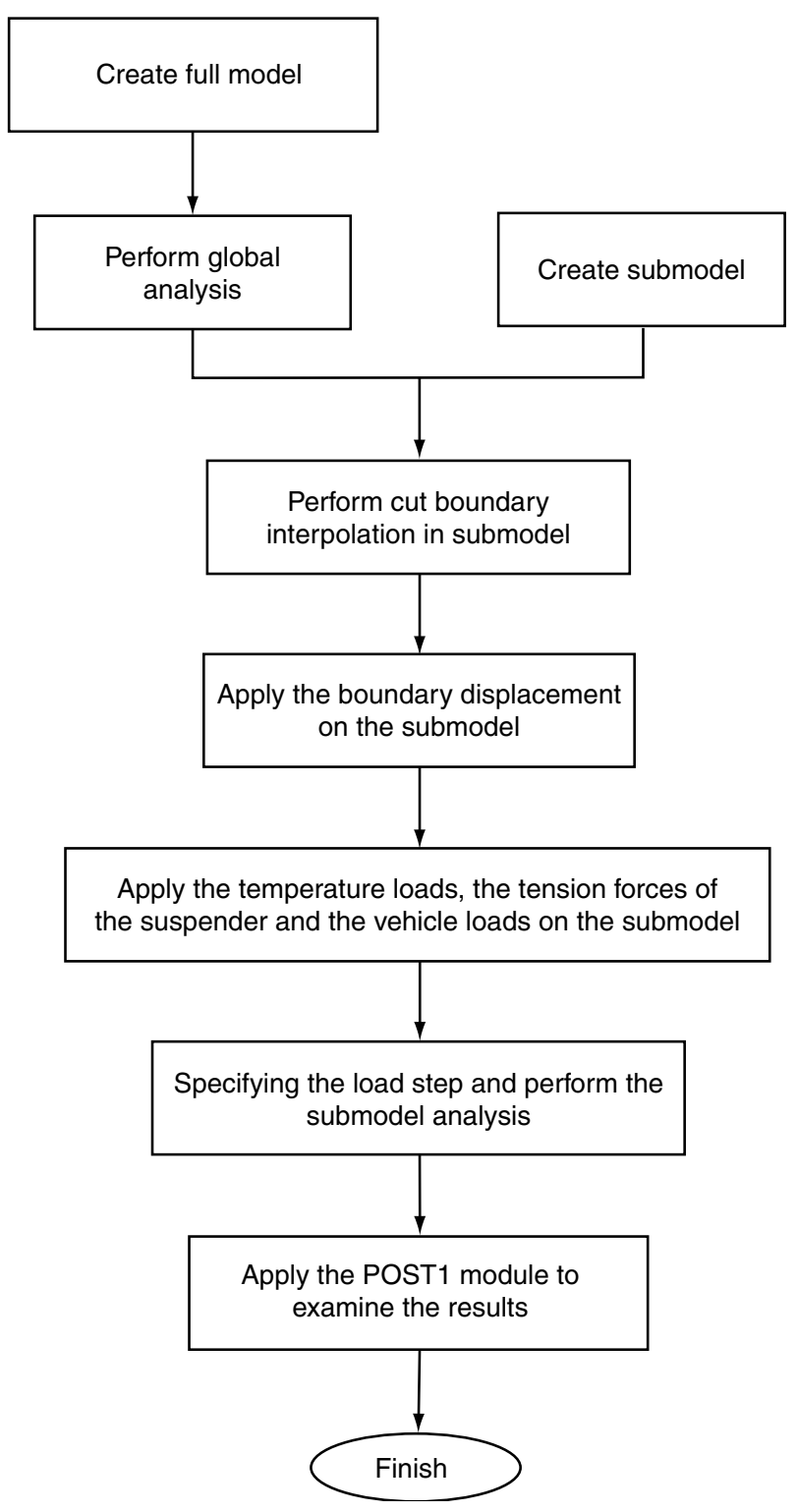

Figure 6. Flow-chart of submodel analysis on the steel box girder

loading step is specified and then the submodel analysis follows. After the submodel analysis finishes, the structural response values of the submodel are obtained from the common result disposition (POST1) module in ANSYS. The submodeling process of the steel box girder, using ANSYS program, is summarized in Figure 6.

\section{FIELD MEASUREMENTS ON THE STRESS OF THE STEEL BOX GIRDER}

In order to examine the design and construction quality, obtain the complete structural condition and provide technical references for conservation and maintenance of RSB, the field load tests including the static and the dynamic test on the bridge were conducted on
January 4-6, 2005, prior to the official opening of the bridge. Because of the significance of the steel box girder, the stress measurements on key sections of the steel box girder under various vehicle loads is one of the main tasks in the field load test (Li et al. 2005).

\subsection{Overview of Vehicle Loads}

Considering the design moment values of the steel box girder, the load efficiency and the turning round of the vehicles, $300 \mathrm{kN}$ weight vehicles were selected as the vehicle loads of the field test, the effect of which was equivalent to the vehicle-20 level in the highway design code. Figure 7 shows the vehicle loads in the field test of RSB and Table 1 shows the technical parameters of the vehicle loads.

The total number of the needed vehicles in the field test was obtained through the calculation of the most unfavorable vehicle load cases according to the design standard live loads and the load efficiency coefficients. 52 vehicles were used as load in the field test based on the calculation. Before the load test, each vehicle were carefully examined and weighed according to the test requirements.

\subsection{Vehicle Load Cases}

There are eight kinds of vehicle load cases in the field test. Among these load cases, case two and three are more unfavorable for the $1 / 4$ span section of the steel box girder. For this reason, they are chosen as two examples in this paper. Table 2 shows the longitudinal vehicle location of load case two and three in the field test of RSB. The transverse vehicle location of the two load cases is shown in Figure 8. The unit is $\mathrm{cm}$ and only the left front wheel of the vehicle is marked in Figure 8. As can be seen from Figure 8, the vehicle location is symmetric in the transverse direction.

\subsection{Measured Points Layout on the Steel Box Girder}

Figure 9 shows the layout of the stress measured points on the 1/4 span steel box girder of RSB. For the sake of measurement convenience, the measured points on the "U" girder, the top and bottom plates were all located between the two adjacent transverse clapboards which contain the 1/4 span section in the longitudinal direction.

In the number of the measured points in Figure 9, "R" represents the right driveway (downstream), "L" represents the left driveway (upstream). "U" represents the top plate, " $D$ " represents the bottom plate and " $M$ " represents the middle of the box girder. As shown in Figure 9, some measured points were located on the top "U" girder, the top and bottom plates in order to obtain the transverse distribution of bending stress of the steel 

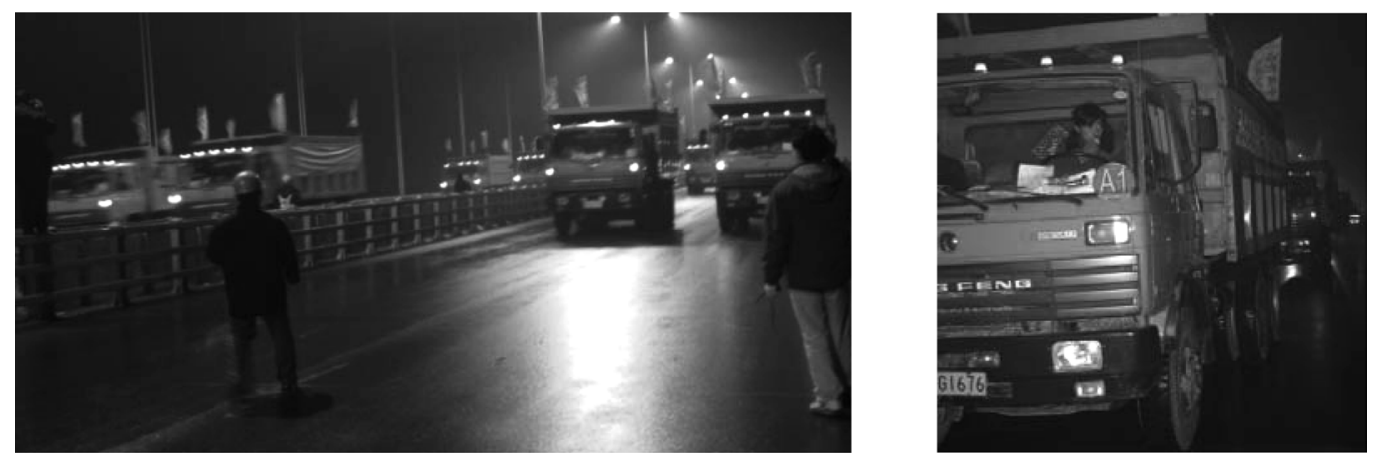

Figure 7. The vehicle loads in the field test of RSB

Table 1. Technical parameters of vehicle loads in the field test of RSB

\begin{tabular}{ccccccc}
\hline \multicolumn{2}{c}{ Axle distance $(\mathbf{m m})$} & \multicolumn{2}{c}{ Wheel distance $(\mathbf{m m})$} & \multicolumn{2}{c}{ Weight (kN) } \\
\hline $\begin{array}{ccccc}\text { Mid and front axle } \\
3500\end{array}$ & Mid and rear axle & Front wheel & Rear wheel & Front axle & Mid and rear axle & Whole weight \\
\hline
\end{tabular}

Table 2. Vehicle load cases in the field test of Runyang Suspension Bridge

\begin{tabular}{cl}
\hline Load case & \multicolumn{1}{c}{ Vehicle load locations } \\
2 & The $1 / 2$ span section of the steel box girder. $(40-52)^{*} .52$ vehicles were arrayed in 13 rows and 4 columns. \\
The distance between two adjacent vehicles is $16.1 \mathrm{~m}$. & The $1 / 4$ span section of the steel box girder. $(17-29)^{*} .52$ vehicles were arrayed in 13 rows and 4 columns. \\
3 & The distance between two adjacent vehicles is $16.1 \mathrm{~m}$.
\end{tabular}

*The numbers in the brackets represent the corresponding number of the suspenders. The central buckle is No. 46 and the maximum number is 91.

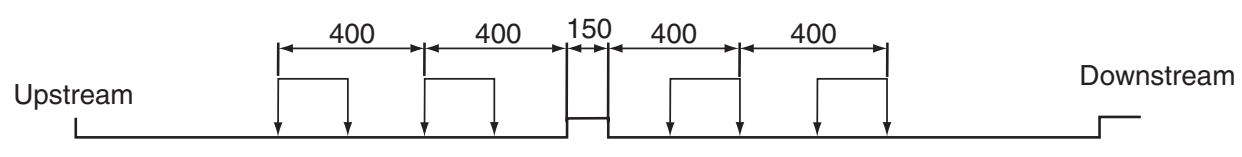

Figure 8. Transverse location of the vehicle loads (Unit: $\mathrm{cm}$ )

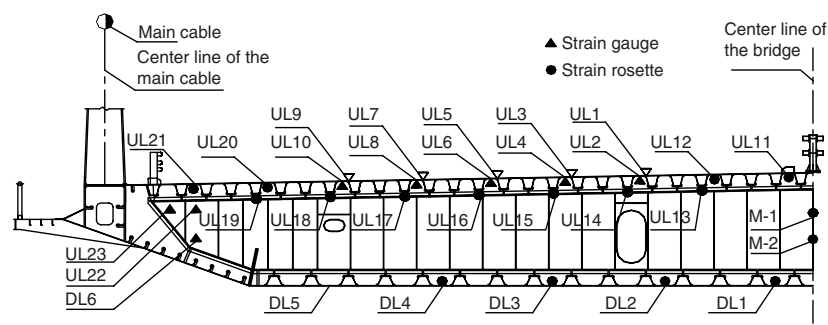

Figure 9. Measured points of L/4 section of the steel box girder

box girder. The points located on top of the transverse clapboards were used to measure the bending deformation of the transverse clapboards.

\section{COMPARISON BETWEEN THE EXPERIMENTAL AND NUMERICAL RESULTS}

\subsection{Choosing the Mesh Size for the Submodel}

Directly relative to the accuracy of results and the computation time, choosing the mesh size for the submodel is of great significance when conducting submodeling analysis. To choose a reasonable mesh size for the submodel of the steel box girder, three submodels with different mesh size were established. They are named as Submodel 1, Submodel 2 and Submodel 3, respectively. The Submodel 2 with 42241 elements was described in Section 3.3. During the submodel meshing, the grid density of the Submodel 1 is set half of the 
Submodel 2, and the grid density of Submodel 3 is set twice of Submodel 2. Consequently, Submodel 1 with 24768 elements is coarser than Submodel 2, while Submodel 3 with 79953 elements has the highest grid density among the three submodels. All of the three types of analysis results are compared with the experimental results, and some of the comparisons are shown in Figure 10.

In Figure 10, the origin of the $\mathrm{x}$-axis represents the center of 1/4 span section. Considering the distance equivalency of every measured point, only two values at the end of the section are shown in the x-axis. The y-axis represents the longitudinal bending stress of the girder distributed along the transverse direction. As shown in Figure 10, in each part of the L/4 section of the steel box girder, the analytical stress values from Submodel 1 is different to those from Submodel 2, but the difference between Submodels 2 and 3 is much smaller. For the bottom plate under load case 2, the largest difference is $2.65 \%$. For the top " $U$ " girder and the top plate under load case 3, the largest differences are $3.70 \%$ and $2.94 \%$, respectively. Therefore, the mesh size of

Distance to the section center $(\mathrm{mm})$

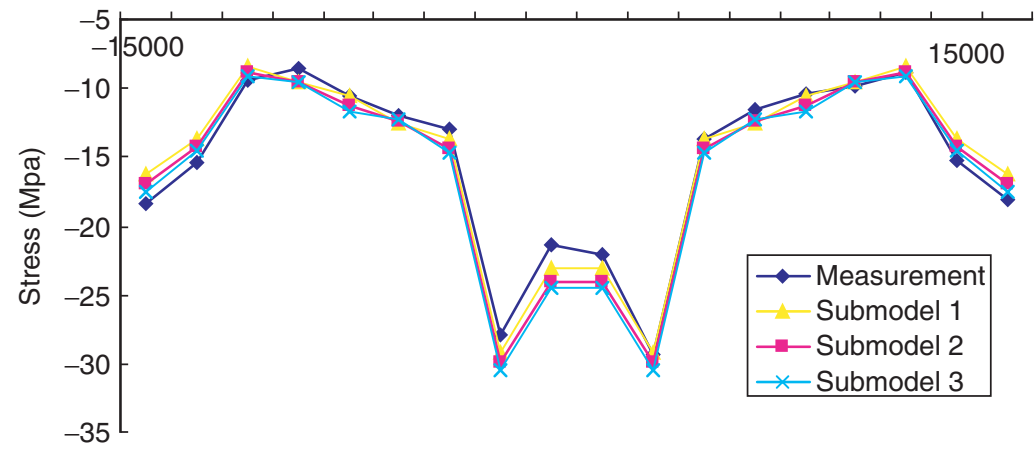

(a) The stress of the top plate under load case 3

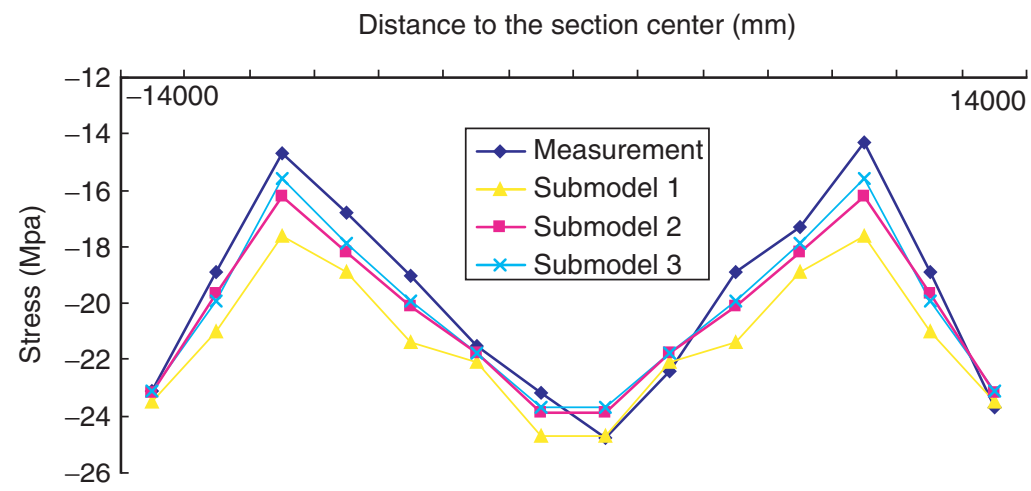

(b) The stress of the top "U" girder under load case 3

Distance to the section center $(\mathrm{mm})$

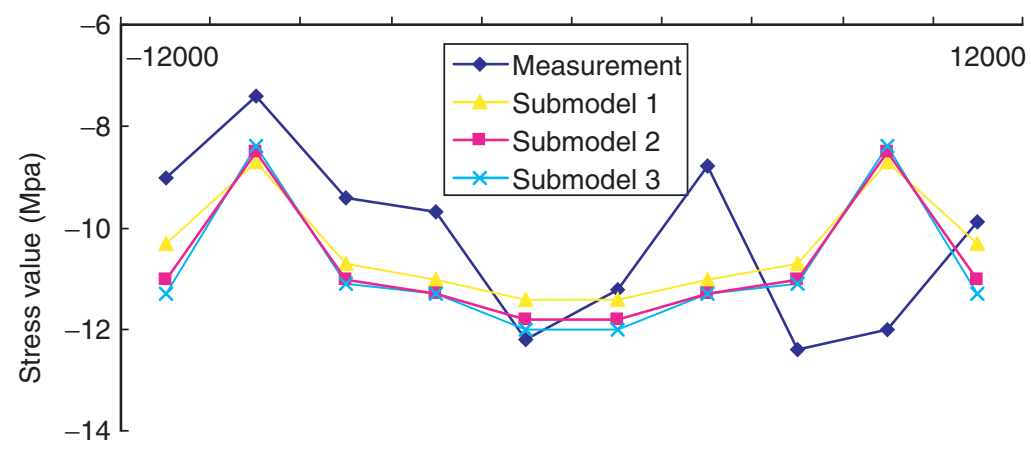

(c) The stress of the bottom plate under load case 2

Figure 10. The stress comparison of L/4 section of the steel box girder using different-scale submodels 
Submodel 2 with 42241 elements is sufficient for yielding accurate analytical stress results of the steel box girder of the RSB, and further increasing of the mesh size will not result in great change in the analysis results. It is necessary to point out that the run time of Submodel 2 is about four and a half hours, while Submodel 3 is about eleven hours, which deserves serious consideration in choosing the mesh size for the submodel of the steel box girder.

\subsection{Transverse Stress Analysis}

Figures 8 to 10 shows the numerical and experimental transverse distribution of bending stress of the top plate, the top "U" girder and the bottom plate of the steel box girder, respectively. In Figures 11 to 13 , the $\mathrm{x}$-axis and $y$-axis have the same meaning in Figure 10.

\subsubsection{Transverse stress analysis on the top plate}

Figure 11 shows the transverse distribution of bending stress of the top plate of L/4 section of the steel box girder under the load case 2 and 3, respectively.

As can be seen from Figure 11, the numerical results from submodel analysis agree with the experimental results well, and the absolute stress values on the end and middle of the measured section are larger than

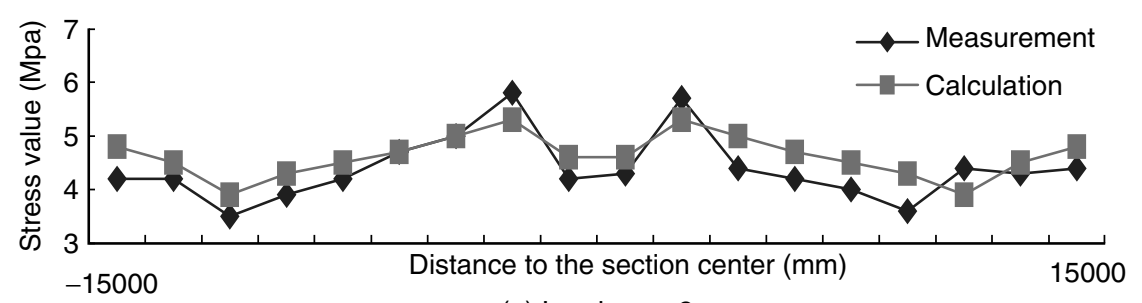

(a) Load case 2

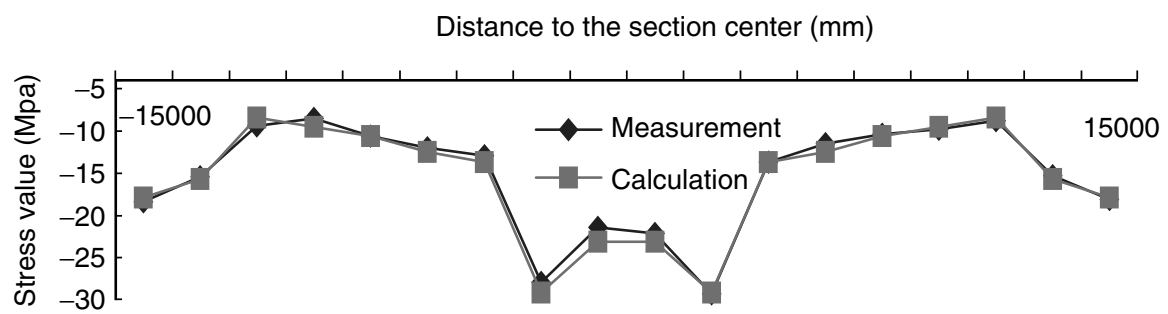

(b) Load case 3

Figure 11. Transverse distribution of bending stress of the top plate of L/4 section

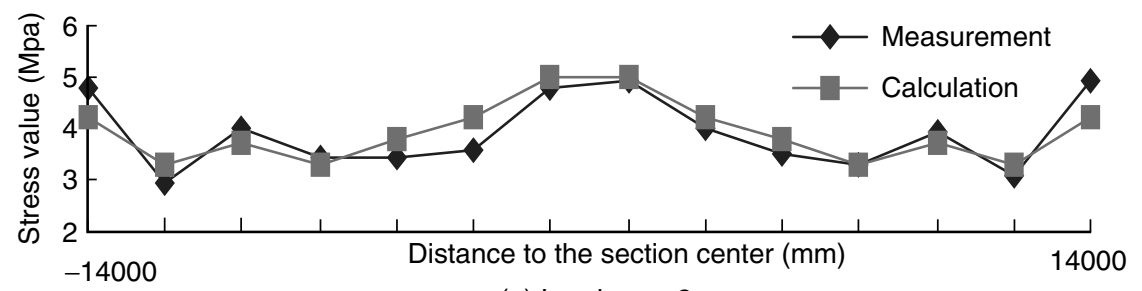

(a) Load case 2

Distance to the section center $(\mathrm{mm})$

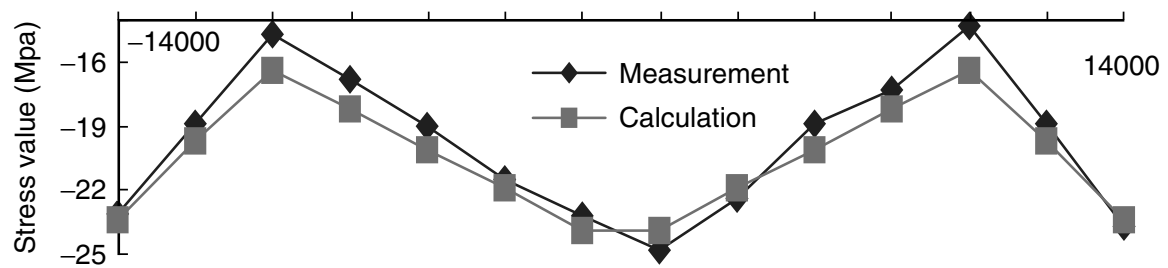

(b) Load case 3

Figure 12. Transverse distribution of bending stress of the top "U" girder of L/4 section 


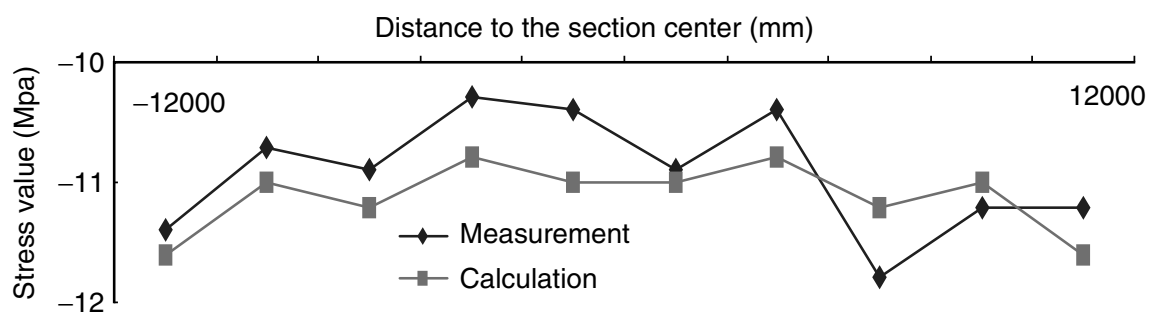

(a) Load case 2

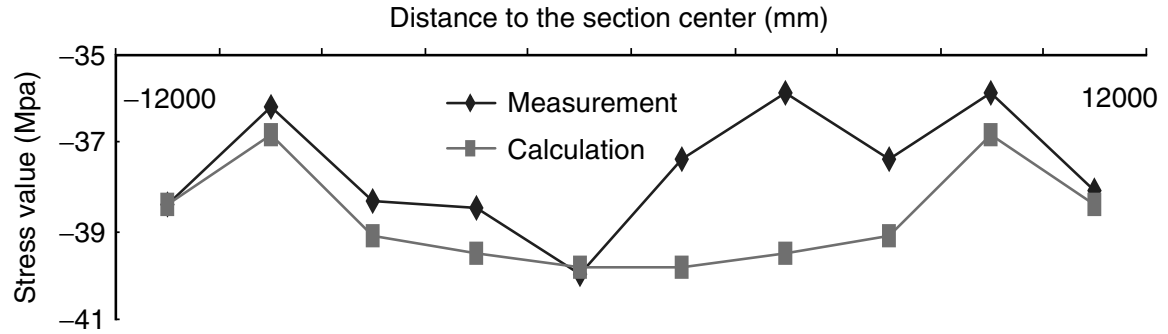

(b) Load case 3

Figure 13. Transvrse stress distribution of the bottom plate of $\mathrm{L} / 4$ section

those on the quarter. Therefore, the transverse distribution of bending stress has an " $\mathrm{M}$ " shape under the load case 2 and a "W" shape under the load case 3. The similar "M" or "W" shapes are also found under other load cases which are caused mainly by two reasons. One is the shear lag effect which makes the top plate stress near the ventro-board greatly larger than that far from the ventro-board. The other is the effect of the transverse slope, which makes the neutral axis distance of the top plate center larger than other locations. According to the assumption of plane section, the stress on the middle of the measured section is much larger. The effect of the local stress effect caused by the vehicle loads is also phenomenal as shown in Figure 11.

\subsubsection{Transverse stress analysis on the top "U" girder}

Figure 12 shows the transverse distribution of bending stress of the top "U" girder under the load case 2 and 3, respectively.

Similarly, the numerical results from submodel analysis and the experimental results greatly consist with each other as shown in Figure 12. The shear lag and the transverse slope effects are again reflected in the transverse distribution of bending stress of the top " $U$ " girder by the " $\mathrm{M}$ " and "W" shapes.

The local stress effect caused by the vehicle loads is noticeable for the same reason. The stress distribution of the top plate differs from that of the top "U" girder. The reason is that the vehicle loads act directly on the former one while indirectly on the latter one because of the transfer of the top plate. Consequently, the stress distribution of the top "U" girder has some obvious sharp angle near the quarter section.

\subsubsection{Transverse stress analysis on the bottom plate}

Figure 13 shows the transverse distribution of bending stress of the bottom plate of the steel box girder under the load case 2 and 3, respectively.

As can be seen from Figure 13, most numerical and experimental results match well; however, a few computed values do not match the experimental results. One possible cause for this difference is the manufacturing defects in the steel box girder. This discrepancy could also be potentially introduced during bridge construction. Another cause could be measurement error during the field test. Because both the vehicle loads and the bridge are symmetric, the stress distribution of the steel box girder should also be symmetric while this is not the case in the measurement results, as shown in Figure 13.

The transverse distribution of bending stress shows that the effect of the shear lag on the bottom plate also exists. Since the bottom plate is flat and it does not directly bear the vehicle loads, the transverse distribution of bending stress of the bottom plate is relatively smoother and the absolute stress values on the middle of the measured section are not larger than those on the other sections. The distribution of the bottom plate differs from that of the top plate. 
Figure 13 also shows that when the vehicle loads act on the measured section directly, the stress level of the bottom plate is much larger than that of the other locations of the steel box girder, and the minimum of the experimental values reaches $35.9 \mathrm{MPa}$ (corresponding to the DR4 measured point). Therefore, special attention should be paid to the high stress level of the bottom plate under the vehicle loads.

\subsection{Longitudinal Stress Analysis}

As introduced in Section 2, the submodeling method is based on St. Venant's principle, so the submodel of the steel box girder selected for stress analysis should have enough length in the longitudinal direction to achieve reasonable accurate results. In order to explain what happens to the bridge deck in the sub-model, the composite action between the full model and the submodel, and whether the length of the submodel of the steel box girder is enough or not, Figures 14 to 16 shows the numerical longitudinal distribution of bending stress of the top plate, the top " $U$ " girder and the bottom plate of the steel box girder, respectively. In Figures 14 to 16 , the origin of the $x$-axis represents the location of the $1 / 4$ span section of the bridge, and $\mathrm{D}$ represents the distance to the $1 / 4$ span section. According to Figure 8, the distances of $4.75 \mathrm{~m}$ and $8.75 \mathrm{~m}$ are selected for plotting because the vehicle loads directly act on the top "U" girder and the top plate at these locations. The bottom plate is not meshed at the exact distances of $4.75 \mathrm{~m}$ and $8.75 \mathrm{~m}$, so they are substituted by $4.85 \mathrm{~m}$ and $8.65 \mathrm{~m}$, respectively. Because of the distance equivalency of every node in the submodel, only two values at the end of the section are shown in the $\mathrm{x}$-axis. The y-axis represents the bending stress of the girder distributed along the longitudinal direction.

As shown in Figures 14 to 16: (1) The stresses near the two boundaries of the submodel are greatly influenced by the exerted displacements from the full model, and the influence length is about $3.0 \mathrm{~m}$ in each of the two boundaries, which proves that the submodel with the length of $32.2 \mathrm{~m}$ is enough to get the accurate stress results at the $1 / 4$ span section. It must be pointed out that the vehicle loads applied near the boundary are another reason that causes the stress disturbing of the two boundaries. (2) The vehicle loads of the field test include the front axle loads and the rear axle loads. The weight of the rear axle loads is 4 times that of the front axle loads, so the influence length of the rear axle loads is larger. As can be clearly seen from Figures 14 to 16, there is a vehicle load exactly on the $1 / 4$ span section of

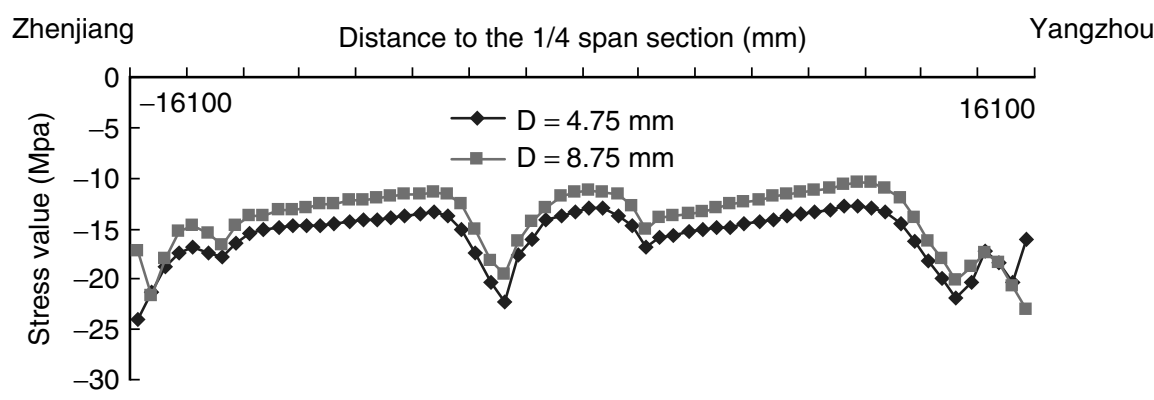

Figure 14. Longitudinal distribution of bending stress of the top plate under load case 3

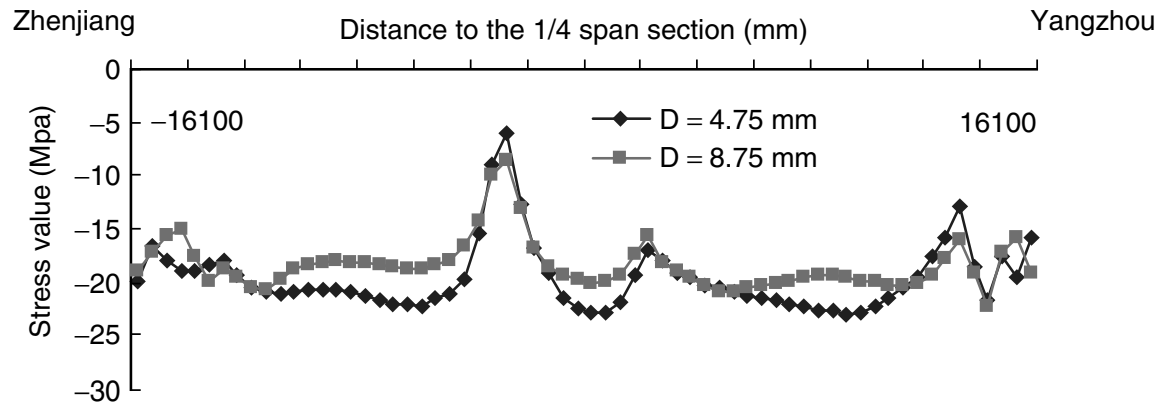

Figure 15. Longitudinal distribution of bending stress of the top "U" girder under load case 3 


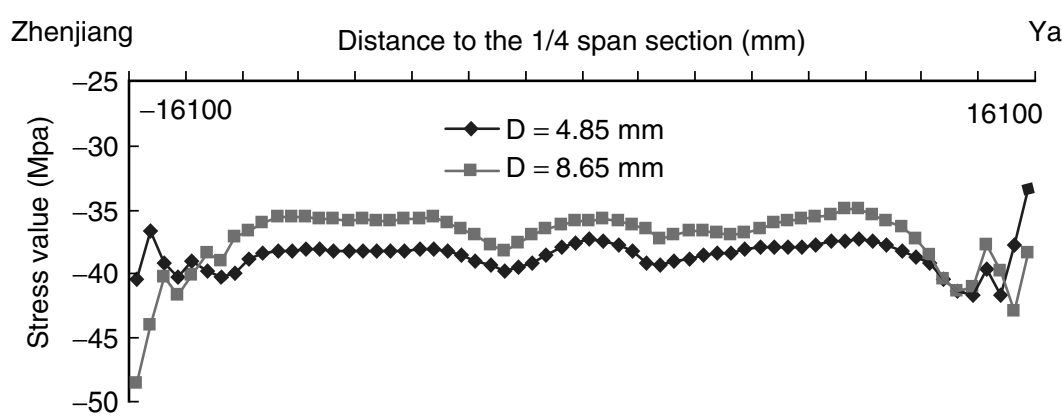

Figure 16. Longitudinal distribution of bending stress of the bottom plate under load case 3

the bridge with the rear axle loads on the Zhenjiang side and the front axle loads on the Yangzhou side, while the longitudinal distribution of bending stress of the bottom plate is relatively smooth because the bottom plate is flat and it does not directly bear the vehicle loads. According to the longitudinal distribution of bending stress above, the influence lengths of the front axle loads and the rear axle loads are about $2 \mathrm{~m}$ and $4 \mathrm{~m}$, respectively. (3) Both on the top plate and on the bottom plate, the longitudinal distributions of bending stress of different distances are very similar, while the longitudinal distribution trends of top " $U$ " girder have some dissimilarities when the distances change. In addition, the longitudinal distribution of bending stress of the bottom plate is relatively smooth, as proved before.

\subsection{Summary of the Stress Distribution on the L/4 Section}

As can be seen from the transverse distribution of bending stress of the steel box girder in Figrues 11 to 13, most of the numerical results agree with the experimental ones. Under two unfavorable load cases of two and three, the stress level is relatively low and much less than the ultimate strength of the structural material. Because the stress level of the transverse clapboard under the above mentioned two load cases is relatively low (only $1 / 10 \sim 1 / 15$ that of the bottom plate), it is not specifically analyzed.

Since the steel box girder is a welded structure, one of its major failure modes is structural fatigue caused mainly by tremendous tension-compression cycling. Although the stress level of the bottom plate is larger than that of the other parts, stress alternating exists in the top plate and the top " $U$ " girder of the L/4 section of the steel box girder, as can be seen from Figures 11 and 12. Compared with that of the top plate, the stress alternating of the top " $U$ " girder is more phenomenal, and the minimum of its amplitude is already 20.1 MPa (corresponding to the measured point UL17). The cause of that is the combined action of vehicle loads on various locations and the elastic restriction of the transverse clapboard. As a consequence, special attention should be given to the top "U" girder in the study of fatigue failure of the steel box girder of RSB.

It is found from Figurs 14 to 16 that the stresses near the two submodel boundaries are greatly disturbed and the influence length is about $3.0 \mathrm{~m}$ in each boundary, and the influence lengths of the front axle and the rear axle of the vehicle loads in longitudinal direction are about $4 \mathrm{~m}$ and $2 \mathrm{~m}$, respectively. The above results can provide theoretical reference for choosing the length of the submodel when carrying out accurate stress analysis on the steel box girder of long span suspension bridges.

\section{CONCLUSIONS}

(1) Single-scale FE model fails to satisfy the requirements of different analysis on the steel box girders of long-span suspension bridges. It is necessary to perform multi-scale FE modeling techniques. As long as the length and the grid density of the submodel are properly selected with adequate level, the submodeling method has high efficiency and accuracy on steel box girder stress analysis, which has been validated by the experimental results from the field test. As a result, the submodeling method can be broadly performed in similar analysis of long span cablesupported bridges.

(2) Choosing proper mesh size for the submodel of the steel box girder is one of the most important issues when carrying out a submodeling analysis. Comparison using submodels with different mesh size should be conducted firstly to obtain an accurate and efficient submodel. As for the steel box girder of RSB, 42241 elements are sufficient for conducting accurate stress analysis on the steel box girder with $32.2 \mathrm{~m}$ length, while maintaining a reasonable computational cost. 
(3) Another key issue during the submodeling analysis on the steel box girder is to determine the length of the submodel. Results show that the composite action phenomenon near the two boundaries of the submodel is very clear, and the influence length is about $3.0 \mathrm{~m}$ in each of the two boundaries. Therefore, the stress locates more than 3 meters to the submodel boundary can be utilized, and the submodel of the steel box girder with the length of $32.2 \mathrm{~m}$ is enough to get accurate stress results.

(4) The shear lag and transverse slope greatly affect the transverse distribution of bending stress of the steel box girder of long span suspension bridges, which make the distribution of the top plate and the top " $\mathrm{U}$ " girder in " $\mathrm{M}$ " and " $\mathrm{W}$ " shapes. On the other hand, the transverse distribution of bending stress of the bottom plate is relatively smoother, for it is flat and does not directly bears the vehicle loads.

(5) The stress level of all parts of the steel box girder under all kinds of unfavorable load cases is relatively low and it is much less than the ultimate strength of the structural material, which proves that the safety coefficient of the RSB under vehicle loads is adequate. Compared with the other parts, the stress in the bottom plate is the largest one under the vehicle loads.

(6) Results show that special attention should be given to the stress alternating existing in both the top plate and the top "U" girder, and the stress alternating in the latter one is more phenomenal than that in the former one. As a result, the top " $U$ " girder should be the focus during the study on the structural health monitoring and the fatigue failure of the steel box girder of long span suspension bridges.

\section{ACKNOWLEDGEMENTS}

The work described in this paper is supported by grants from the Key Project of the National Science Foundation of China (NSFC) (Grant No. 50538020), the Outstanding Youth Fund of NSFC (Grant No. 50725828), the NSFC for Young Scholars (No. 50908046) and the Ph.D. Programs Foundation of Ministry of Education of China (Grant No. 200802861012)

At the same time, the authors would like to express their sincere gratitude to their colleagues in Structural Health Monitoring Institute and the Structural Test Center of Southeast University for their great support to the contribution.

\section{REFERENCES}

Bogdanovich, A.E. and Kizhakkethara, I. (1999). "Three-dimensional finite element analysis of double-lap composite adhesive bonded joint using submodeling approach", Composites: Part B, Vol. 30, No. 6, pp. 537-551.

Chan, T.H.T., Guo, L. and Li, Z.X. (2003). "Finite element modeling for fatigue stress analysis of large suspension bridges", Journal of Sound and Vibration, Vol. 261, No. 3, pp. 443-464.

Che, Y. and Song, Y.P. (2003). "Three-dimensional nonlinear analysis of orifice of high arch dam", Journal of Dalian University of Technology, Vol. 43, No. 2, pp. 218-222. (in Chinese)

Cormier, N.G., Smallwood, B.S., Sinclair, G.B. and Meda G. (1999). "Aggressive submodelling of stress concentrations", International Journal for Numerical Methods in Engineering, Vol. 46, No. 6, pp. 889-909.

De Langhe, K., Vandepitte, D. and Sas, P. (1997). “A combined dynamic-static finite element model for the calculation of dynamic stresses at critical locations", Computer and Structures, Vol. 65, No. 2, pp. 241-254.

Ernst, J.H. (1965). "Der E-modul von seilen unter berücksichtigung des durchhanges", Der Bauingenieur, Vol. 40, No. 2, pp. 52-55. (in Germany)

Hsu, Y.T. and Fu, C.C. (2002). "Application of EBEF method for the distortional analysis of steel box girder bridge superstructures during construction", Advances in Structural Engineering, Vol. 5, No. 4, pp. 211-221.

Jaishi, B. and Ren, W.X. (2005). "Structural finite element model updating using ambient vibration test results", Journal of Structural Engineering, ASCE, Vol. 131, No. 4, pp. 617-628.

Li, A.Q. (2005). Report on Field Test of Runyang Yangtse River Bridge, Technical Report, College of Civil Engineering, Southest University, Nanjing, China. (in Chinese)

Li, A.Q. and Wang, H. (2006). Report on Finite Element Analysis of Runyang Yangtse River Bridge, Technical Report, College of Civil Engineering, Southest University, Nanjing, China. (in Chinese)

Li, A.Q. and Wang, H. (2007). "Stress analysis on steel box girders of super-long-span suspension bridges with submodel method", Engineering Mechanics, Vol. 24, No. 2, pp. 80-84.

Mottershead, J.E. and Friswell, M.I. (1993). "Model updating in structural dynamics: A survey", Journal of Sound and Vibration, Vol. 167, No. 2, pp. 347-375.

Ou, J.P. (2003). "Some recent advances of intelligent health monitoring systems for civil infrastructures in Mainland China", Proceedings of the $1^{\text {st }}$ International Conference on Structural Health Monitoring and Intelligent Infrastructure, Tokyo, Japan, pp. 131-144.

Rabinovich, V.L. and Sarin, V.K. (1996). "Modelling of interfacial fracture", Materials Science and Engineering: A, Vol. 209, No. 1, pp. 82-90. 
Sennah, K.M. and Kennedy, J.B. (2002). "Literature review in analysis of box-girder bridges", Journal of Bridge Engineering, ASCE, Vol. 7, No. 2, pp. 134-143.

Sinclair, G.B., Beisheim, J.R., Epps, B.P. and Pollice, S.L. (2000). "Towards improved submodeling of stress concentrations", Proceedings of the $9^{\text {th }}$ International ANSYS Conference, Pittsburgh, Pennsylvania, USA.

Swanson Analysis Systems Inc (SASI) (2004). ANSYS User's Manual, Version 8.0, Houston, Pennsylvania, USA.

Wang, H., Li, A.Q. and Miao, C.Q. (2005). "FE model updating and validating of Runyang Suspension Bridge based on SHMS", Journal of Southeast University (English Edition), Vol. 21, No. 4, pp. 474-479.
Wang, X., Mieth, U. and Cappelletti, A.M. (2004). "Numerical methods for design of bonded joints for ship structures", Proceedings of the Institution of Mechanical Engineers, Part M: Journal of Engineering for the Maritime Environment, Vol. 218, No. 4, pp. 247-258.

Xu, W., Li, Z. and Zhang, X.N. (2004). "Application of submodeling method for analysis of deck structure of diagonal cable-stayed bridge with long span", China Civil Engineering Journal, Vol. 37, No. 6, pp. 30-34. (in Chinese)

Zhang, Q.W. and Sun, L.M. (2002). "FE model updating of suspension bridge based on vibration measurements", Proceedings of the $7^{\text {th }}$ International Symposium on Structural Engineering for Young Experts, Beijing, China, pp. 793-800. 
Copyright of Advances in Structural Engineering is the property of Multi-Science Publishing Co Ltd and its content may not be copied or emailed to multiple sites or posted to a listserv without the copyright holder's express written permission. However, users may print, download, or email articles for individual use. 